\title{
Variación pragmático-discursiva de la segunda persona del singular en el español de Chile: una propuesta de análisis multifuncional
}

Discourse-pragmatic variation of the second person singular in Chilean Spanish:

A multifunctional analysis proposal

\section{Marcela Rivadeneira Valenzuela \\ Universidad Católica de Temuco Chile}

\section{Lissette Mondaca Becerra}

Universidad Católica de Temuco chile

\section{Paulina Pulido Astorga}

Universidad Católica de Temuco Chile

\section{Karen Barra Pereira}

Universidad Católica de Temuco Chile

Marcela ]. L. Rivadeneira Valenzuela: Departamento de Lenguas y Traducción, Facultad de Artes y Humanidades, Universidad Católica de Temuco, Chile. I Correo electrónico: mrivadeneira@uct.cl

Lissette Mondaca Becerra: Departamento de Lenguas y Traducción, Facultad de Artes y Humanidades, Universidad Católica de Temuco, Chile. I Correo electrónico: lissettemondaca@gmail.com

Paulina Pulido Astorga: Departamento de Lenguas y Traducción, Facultad de Artes y Humanidades, Universidad Católica de Temuco, Chile. | Correo electrónico: ppulido.astorga@gmail.com

Karen Barra Pereira: Departamento de Lenguas y Traducción, Facultad de Artes y Humanidades, Universidad Católica de Temuco, Chile. | Correo electrónico: kbarra2010@alu.uct.cl 


\section{Resumen}

El paradigma de la segunda persona del singular en Chile presenta tres formas de tratamiento: el tuteo, el voseo y el ustedeo, todos parte de un complejo sistema que es distintivo dentro del mundo hispanohablante (Benavides, 2003). Además de los aspectos morfosintácticos, desde el plano de la variación lingüística es interesante destacar el empleo del sistema pronominal para transmitir funciones comunicativas específicas. En este sentido, el objetivo principal del presente estudio es analizar los distintos usos pragmático-discursivos de la segunda persona de singular en el español de Chile. Para ello, se propone una categorización en la que se distinguen distintas funciones: a) tratamiento directo (uso deíctico tradicional), b) usos no deícticos, c) discurso referido y d) marcadores discursivos. Con el fin de llevar a cabo un análisis integral, se han relacionado las variables recién descritas y los tratamientos pronominales según el factor morfosintáctico. En cuanto al corpus, hemos utilizado datos orales correspondientes a entrevistas sociolingüísticas. Nuestros resultados indican que las categorías aquí planteadas representan de manera adecuada el carácter multifuncional del sistema de segunda persona, el cual es utilizado por los hablantes como estrategia estilística para dotar a los enunciados de valores comunicativos específicos, valores que trascienden el saber personal y proyectan un conocimiento colectivo acerca de las normas sociales de la lengua.

Palabras clave: segunda persona del singular; variación lingüística; español de Chile.

\section{Abstract}

The second person singular Chilean paradigm presents three forms of address: tuteo, voseo and ustedeo, all part of a distinctive complex system within the Spanish American world (Benavides, 2003). Apart from morphosyntax, from the field of linguistic variation it is important to highlight the use of the pronominal system in order to transmit specific communicative functions. In this sense, the main goal of the present study is to analyze the distinctive discourse-pragmatic dimensions in the usage of second person singular in Chilean Spanish. Therefore, a typology with four different functions is proposed: a) Direct address (traditional deictic usage), b) Reproduced address, c) Non-deictic usage, d) Discourse markers. For a more integral analysis these variables have been related to pronominal address, according to a 
morphosyntactic factor. The oral corpus we have used is composed of sociolinguistic interviews. Our results indicate that the categories here proposed represent adequately the multifunctional character of the second person system, which is employed by speakers as a stylistic strategy to provide utterances with specific communicative values that transcend personal understanding and project a collective knowledge about the social norms of language.

Keywords: second person singular; linguistic variation; Chilean Spanish. 


\section{Introducción}

\subsection{Enfoques multifuncionales en el análisis de la segunda persona de sin- gular}

En términos generales, gran parte de los estudios abocados a la segunda persona gramatical se encuentran asociados a su función deíctica tradicional. No obstante, en el uso cotidiano es posible distinguir diversos usos, cada uno en sintonía con distintas estrategias enunciativas, proyectando "[...] la cultura del comportamiento de una sociedad y [...] las actitudes de los hablantes hacia los interlocutores [...]. De ahí que [las formas y fórmulas de tratamiento] tiendan a variar en todas las dimensiones de la lengua" (Hummel, Kluge y Vázquez Laslop, 2010: 15). Como veremos en este trabajo, dichas variaciones se extienden hasta el plano pragmático-discursivo, nivel que ha sido escasamente estudiado. De hecho, de todos los estudios sobre la segunda persona singular recabados hasta la fecha, las únicas investigaciones que se conoce han abordado una perspectiva multifuncional corresponden a Biq (1991), Kluge (2005b) y Fernández Mallat (2011). Biq (1991: 308) analiza los diferentes usos del pronombre de segunda persona singular ni en un corpus conversacional de chino mandarín. El autor describe cuatro ámbitos o dimensiones de uso de ni: la 'proposicional', 'impersonal', 'dramática' y ‘metalingüística' (nuestra traducción). La categoría proposicional corresponde al uso deíctico canónico; la impersonal, a la sustitución de la primera tipología por un uso indefinido; la dramática, al cambio del marco de referencia desde la situación comunicativa a la situación descrita; por último, la metalingüística sirve como vocativo e indica la atención del oyente hacia el contenido proposicional. El autor concluye que, a diferencia de los usos de ni en su función impersonal y dramática, su utilización como marco metalingüístico y proposicional es claramente deíctica, en tanto la primera señala el rol de participante en la situación comunicativa y la segunda señala al individuo que cumple ese rol. De esta forma, "Ios usos impersonales, dramáticos y metalingüísticos de ni comparten la característica de ser herramientas gramaticales que refuerzan la implicancia del oyente en lo que se está comunicando" (Biq, 1991: 320, nuestra traducción).

Por su parte, Kluge (2005b) realiza un estudio sobre las formas de tratamiento empleadas por informantes originarias del sur de Chile y con trayectorias de migración, en especial mujeres que anteriormente se habían dedicado a labores del hogar en la capital del país. La investigación de Kluge destaca por su aporte descriptivo en aspectos como la alternancia pronominal, si bien lo más interesante para nuestro trabajo son las tres dimensiones de variación estilística que la autora identifica como 'tratamiento directo', 'discurso directo reproducido' y ‘formas generalizadoras'. La autora concluye que estos tres contextos deben estudiarse en su conjunto, como ocurre con el caso de los usos impersonales. Asimismo, pese a que se trata de un corpus pequeño, Kluge distingue diferencias de uso que podrían ser atribuibles a diferencias regionales. Por último, Fernández Mallat (2011) replica parcialmente el análisis de Kluge (2005b) en un estudio de caso en contexto de contacto dialectal. 
Se trata de una investigación realizada con hablantes chilenos residentes en Canadá, a los cuales se aplican entrevistas libres en dos contextos comunicativos (en presencia exclusiva de chilenos y en presencia de otros hispanohablantes). Los resultados de Fernández Mallat sugieren que la elección de las formas de tratamiento de voseo y tuteo varía según se trate del contexto, de acuerdo a la tipología propuesta por Kluge (2005b) y que el autor denomina 'tratamiento directo', 'tratamiento directo reproducido' y 'experiencias de vida generalizables'. Se constata que el voseo es predominante en presencia de chilenos en los tres contextos de uso, a diferencia del tuteo, que es favorecido en presencia de otros hispanohablantes. Así, "Ios informantes entrevistados no desplazan las formas verbales voseantes a favor de las tuteantes [...], sino que se hacen bidialectales, de manera que emplean una u otra forma en función de los factores textuales y contextuales que marcan el discurso" (Fernández Mallat, 2011: 56).

Queda en evidencia que estas perspectivas representan un aporte más dinámico y comprensivo sobre los distintos usos de la segunda persona en el habla oral. En este sentido, Ilama la atención que los únicos dos estudios sobre el español se basen en datos de la variedad chilena. Siendo este, justamente, nuestro objeto de estudio, creemos importante continuar con las pesquisas de análisis empírico que nos permitan generar proyecciones en cuanto a la multifuncionalidad de un sistema que tiene la "capacidad de trascender el ámbito referencial" (Serrano y Aijón Oliva, 2012: 541) hacia otros usos discursivos, considerando que la variación contextual podría ser un factor determinante en la explicación de las reglas internas que rigen la elección de las formas de tratamiento (Blas Arroyo, 1995, en Carvalho, 2010). Siguiendo esta línea, en el presente estudio nos hemos propuesto analizar los distintos contextos de uso de la segunda persona del singular en el español de Chile. Para ello, se extraen datos de un proyecto de investigación sobre los tratamientos pronominales en Chile ${ }^{1}$. El corpus de trabajo consta de 180 horas de entrevistas sociolingüísticas a informantes originarios de cuatro zonas dialectales de Chile (correspondientes a diez núcleos urbanos), los cuales han sido estratificados según factores extralingüísticos. Si bien se trata de una investigación de corte sociolingüístico, en este trabajo ahondaremos principalmente sobre los aspectos pragmático-discursivos de la variación.

A continuación ahondaremos brevemente sobre algunos conceptos teóricos básicos que dan sustento a nuestro estudio. Posteriormente presentaremos la metodología empleada, el análisis de las variables que se proponen y finalmente un apartado de discusión y conclusiones.

1 Proyecto Fondecyt 11110211 "El voseo en Chile: Un cambio lingüístico en desarrollo. Aspectos internos y externos de la variación". Dicha investigación es de corte exploratorio y corresponde a la primera realizada en Chile que abarca el estudio de la segunda persona del singular desde un enfoque geo y sociolingüístico. 


\subsection{La variación lingüística}

El presente estudio se basa en supuesto un variacionista, en tanto se conciben las distintas manifestaciones de una variable como "formas diferentes de decir lo mismo" (Moreno Fernández, 2009 [1998]: 22). En este sentido, nos hacemos partícipes de la premisa descriptivista de la sociolingüística, entendiendo que las diversas realizaciones de un rasgo lingüístico determinado no pueden ser vetadas en tanto sean utilizadas en las distintas dimensiones del habla cotidiana, pues son los usuarios mismos quienes dan vida a la lengua. De esta forma, si consideramos la importancia de quienes producen la lengua, debemos también tomar en cuenta todos aquellos factores que caracterizan a los hablantes. La sociolingüística variacionista es "una disciplina que ha evolucionado durante las últimas cuatro décadas y que integra aspectos sociales y lingüísticos del lenguaje [...], cuyo enfoque busca presentar un modelo de lenguaje que permita acomodar las paradojas del cambio lingüístico" (Tagliamonte, 2006: 4, nuestra traducción). Tradicionalmente, se ha planteado que el estudio de la variación lingüística solo puede aplicarse a niveles concretos de la lengua, es decir, a los componentes fonético-fonológico y léxico. Así, mientras algunos autores como Lavandera (1978) cuestionan "la posibilidad de extender la noción de variable lingüística a otros niveles descriptivos" (Silva-Corvalán, 2001: 129), otros proponen la aplicación de técnicas de análisis cuantitativos sobre casos de variación sintáctica (Labov, 1972b; Sankoff, 1973; Sankoff, 1988b). En años más recientes este concepto se ha ampliado a los ámbitos pragmáticos y discursivos, siempre en situaciones en donde la comparación de dos enunciados no conlleva diferencias semánticas o funcionales (García, 1986; Serrano, 1999; San Martín, 2004-2005, 2011; Guerrero, 2011a, 2011b; San Martín y Guerrero, 2013).

Siguiendo esta propuesta y para efectos de este estudio, nos abocaremos a dar cuenta de la variación tomando en consideración aspectos pragmático-discursivos. En relación a la delimitación de los contextos de empleo de la segunda persona del singular, nos basaremos parcialmente en las propuestas antes mencionadas de Biq (1991) y Kluge (2005b), a partir de lo cual proponemos la distinción de cuatro variables, cada una correspondiente a una dimensión de uso pragmático-discursivo específico: a) tratamiento directo, b) discurso referido, c) uso no deíctico y d) marcador discursivo. Antes de pasar a nuestro planteamiento de análisis, describiremos brevemente el tipo de corpus y la metodología que hemos empleado para nuestro estudio.

\section{Metodología}

El corpus que compone el presente estudio se basa en muestras de habla semi-espontánea obtenidas a través de la grabación de entrevistas sociolingüísticas, recolectadas entre marzo de 2012 y diciembre de 2014. Los datos con los que hemos trabajado han sido extraídos del 
proyecto base 2 . En cuanto al análisis morfosintáctico, este se centra principalmente en las formas verbales de segunda de singular, aunque se incluyen en los ejemplos algunos casos con usos pronominales en función de sujeto; en relación al voseo, se ha decidido abordar principalmente las realizaciones verbales y la tipología ‘culta' (Torrejón, 1986), es decir, las combinaciones de flexión voseante con pronombre sujeto tú, pues son los casos más frecuentes en nuestro corpus. En otros aspectos gramaticales, se excluyen del análisis el modo imperativo y el pretérito indefinido de indicativo, pues en etapas preliminares se ha comprobado que no existen ocurrencias de voseo en estas formas, de manera tal que no se puede realizar una comparación congruente con los paradigmas de tuteo y ustedeo³ (Carvalho, 2010; Helincks, 2015; Rivadeneira, 2016). En síntesis, y salvo los casos mencionados anteriormente, se han analizado todas las ocurrencias verbales de la segunda persona de singular en relación a los factores pragmático-discursivos propuestos.

\section{Análisis}

\subsection{Tratamiento directo}

Corresponde a la función deíctica tradicional de la segunda persona del singular, con referencia directa al interlocutor. En español ha sido ampliamente estudiado, tanto desde perspectivas históricas como sincrónico-regionales (Eguiluz, 1962; Fontanella de Weinberg, 1970, 1971, 1977, 1979, 1987, 1993, 1999; Torrejón, 1986, 1991, 2010a, b; Dworkin, 1988a, 1988b; Bertolotti, 2004; Carricaburo, 2004; entre muchas otros).

En general, el paradigma pronominal hispanoamericano está conformado por el voseo, tuteo y ustedeo, si bien solo estos dos últimos están aceptados formalmente (excepto en Ar-

2 Equivalentes a 180 horas de entrevistas a informantes estratificados según sexo y edad, de las siguientes ciudades: Arica, Iquique, Coquimbo, Valparaíso, Santiago, Concepción, Temuco, Coyhaique, Punta Arenas y Chiloé. Los grupos etarios son tres: joven (18-24 años), adulto-joven (25-34 años) y adulto (35-54 años).

3 Se ha planteado la discusión sobre cómo determinar si una forma de imperativo o pretérito indefinido corresponde a voseo o tuteo, si la flexión verbal para ambos es claramente tuteante (Helincks, 2015). Torrejón (2010a) plantea que siempre es el contexto lingüístico previo el que da las pistas sobre el paradigma predominante, mientras que Helincks (2015) advierte que es recomendable no incluir dichos datos en los análisis para evitar ambigüedades. Por nuestra parte, concordamos con ambos autores, para lo cual además proponemos que las formas de pretérito indefinido -stes no corresponden a formas morfológicas de voseo, sino que son el resultado de un proceso de analogía con la -s final de la flexión tuteante (Rivadeneira, 2009), mientras que las formas de voseo en imperativo del tipo rioplatense andá, comé, vení no son propias de la variedad chilena, sino que se dan esporádicamente en áreas rurales colindantes con Argentina, meramente por influjo dialectal (Torrejón, 1986). 
gentina, en donde el voseo es incluido en el sistema educativo en 1982 y hoy es tratamiento casi exclusivo para la segunda persona singular). En Chile el sistema se resume de la siguiente manera 4 :

\section{TABLA 1}

Formas de tratamiento en Chile

\begin{tabular}{lll}
\hline \multicolumn{1}{l}{ Tuteo } & tú amas, tienes, sientes \\
\hline Ustedeo & Mixto verbal & tú amai, teníh, sentíh \\
\cline { 2 - 3 } Voseo & Auténtico & vos amai, teníh, sentíh \\
\cline { 2 - 3 } & Mixto pronominal & vos amas, tienes, sientes \\
\hline
\end{tabular}

Es interesante notar el paradigma interno de voseo con sus distintas categorías: voseo mixto verbal, es decir, la combinación entre pronombre sujeto tú y flexión voseante (también denominado voseo culto); voseo auténtico, combinación de vos con su correspondiente forma verbal de voseo; y voseo mixto pronominal, donde vos se acompaña de flexión de tuteo (Torrejón, 1986). Se constata, de esta forma, que en el plano morfosintáctico existen al menos cinco estructuras posibles para la segunda persona del singular, independiente de la clase verbal, a excepción del verbo ser, para el cual se distinguen siete tipologías voseantes.

\section{TABLA 2}

Formas de voseo para el presente de indicativo del verbo ser

\begin{tabular}{ll}
\hline \multirow{2}{*}{ Voseo mixto verbal } & \multicolumn{1}{c}{ tú soi } \\
\cline { 2 - 2 } tú eríh \\
\hline \multirow{2}{*}{ tú soh } \\
\hline voseo auténtico & $\frac{\text { vos soi }}{\text { voseríh }}$ \\
\hline vos soh \\
\hline
\end{tabular}

4 Utilizamos la terminología clásica propuesta por Torrejón (1986) para las distintas tipologías de voseo. 
En efecto, como se observa en las tablas recién expuestas (especialmente la tabla 2), el caso de Chile es único y exclusivo con respecto al resto de variedades voseantes (Rivadeneira y Clua, 2011; Rivadeneira, 2016). En este sentido, es importante mencionar que no se tiene certeza sobre el origen de la variación morfosintáctica en el presente de indicativo de ser, si bien Morales Pettorino (1998-1999) comenta sobre la novedosa aparición de la forma eréi, como la denomina el autor, la que observa especialmente en el lenguaje juvenil universitario de Valparaíso y atribuye como desambiguación de soi5. Al respecto, González (2002) realiza un estudio exploratorio en hablantes santiaguinos y concluye que la forma eríh es preferida por los jóvenes de la clase media alta, mientras que soi la emplearían únicamente los jóvenes de clase baja, por lo que podría tratarse de rasgos distintivos de estratos sociales. Acerca de la forma soh, que presenta morfología rioplatense (sos) con aspiración de -s final, no se documenta en ningún estudio previo, si bien se escucha recurrentemente en el habla juvenil masculina de la ciudad de Temuco, por lo que puede tratarse más bien de un rasgo diatópico (Rivadeneira, 2016).

Antes de continuar, quisiéramos destacar el hecho de que el voseo es un rasgo propio del español de Chile, empleado históricamente en la norma culta —como se evidencia a partir de documentos de los siglos XVI y XVII (Araya, 1995; Rivadeneira y Cautín-Epífani, 2015). No obstante, el cambio más significativo que se desprende de la evolución del voseo se encuentra en el siglo XIX, como consecuencia de modificaciones en el sistema escolar tras las reformas educativas de Bello, a partir de lo cual se 'sanciona' socialmente el empleo de vos, lo que, no obstante, deja paso y conlleva a la expresión semántico-pragmática del pronombre a través de la flexión verbal (Torrejón, 1986; Sweeney, 2013; Rivadeneira y Clua, 2011; Rivadeneira, 2016).

De esta forma, encontramos, por un lado, que la variedad actual de voseo que es más empleada en la lengua estándar es aquella en la que se combina morfosintácticamente el pronombre tú con forma verbal voseante, tipología que hemos descrito previamente como voseo culto o voseo mixto verbal (Torrejón, 1986). Por otro lado, es importante señalar que la ocurrencia de las formas pronominales en función de sujeto es muy baja, siguiendo la tendencia pro-drop del español, de manera tal que las tipologías mencionadas se subsumen básicamente a la realización verbal de voseo, para el cual, aunque no haya un sujeto pronominal, se asume un tú y no un vos, ya que este corresponde a una forma lingüísticamente

5 No concordamos con la opinión de Morales Pettorino (1998-1999) sobre este punto, pues se atribuye a la forma voseante soi un sincretismo con la primera persona singular, soy, lo que según el autor provoca confusión. No obstante, sabemos que dichas homologías no deben tomarse como lexemas aislados, y que es el mismo contexto comunicativo el que las desambigua. 
marcada dentro del paradigma voseante en el español de Chile, por las razones históricas que subyacen al desarrollo de este rasgo. De igual forma, al comparar los sistemas de voseo y tuteo, se observa que, si bien ambos tratamientos son de tipo simétrico, existe una tendencia a desplazar el uso de tuteo hacia estilos más formales y neutros (Hummel, 2010; Rivadeneira, 2016), característico de situaciones donde no hay mayor confianza o cercanía entre los interlocutores. En este sentido, el tuteo se presenta como forma marcada, pues su uso se condiciona a un tipo de habla más consciente y monitoreada, con mayor presencia normativa y correctiva, a diferencia del voseo, que surge de forma espontánea y natural en la lengua vernácula (Rivadeneira, 2016), especialmente en contextos de solidaridad y cercanía (Torrejón, 1986, 1991). En cuanto al ustedeo, cabe señalar que, independiente del grado de formalidad, este se emplea principalmente como marca de respeto y distancia en situaciones asimétricas, en las que priman diferencias de edad, jerarquía o estatus. No obstante, en otros ámbitos más íntimos, el ustedeo es propio del lenguaje entre parejas (Torrejón, 1986) y de familiares adultos hacia niños pequeños, como rasgo representativo de cariño y afecto (Rivadeneira, 2016) 6 .

En el análisis de nuestro corpus los usos de tratamiento directo que detectamos corresponden a instancias en las que el informante se dirige a su entrevistadora. Por su incidencia pragmática, cabe señalar que la mayor parte de las entrevistas fueron realizadas por jóvenes mujeres, estudiantes universitarias, de la ciudad de Temuco. Dado que los datos corresponden a distintos puntos geográficos del país, la mayor parte de las interacciones se realizan en una instancia en la que ambos interlocutores son desconocidos ${ }^{7}$. En general, las jóvenes se dirigen hacia los informantes de su mismo grupo etario y a los del grupo generacional adulto-joven mediante voseo, y al resto de informantes adultos mediante ustedeo. Hemos comprobado, no obstante, que dicho factor (forma de tratamiento empleada por la entrevistadora) no tiene mayor incidencia sobre los informantes, como señalan estudios anteriores (Carvalho, 2010). Tampoco hemos evidenciado variación a este respecto en cuanto a la variable sexo (relación mujer-hombre, mujer-mujer en el contexto de entrevista).

6 Es importante notar la alternancia que se produce en los sistemas pronominales bajo el efecto del factor emocional. Así, se puede pasar del tratamiento de cariño de usted a un tú en momentos de enfado, como cuando una pareja discute o una madre llama la atención a su hijo pequeño. En este sentido, se observa claramente el carácter marcado de la forma de tuteo que proponemos en este y otros estudios (Rivadeneira, 2016).

7 Salvo las entrevistas de Iquique (realizadas por la investigadora responsable), Temuco, Coyhaique y Punta Arenas, en donde gran parte de los informantes eran familiares, amistades o conocidos de las entrevistadoras. 
Comenzaremos la serie de ejemplos ${ }^{8}$ con casos de voseo, ya que es la forma predominante en nuestro corpus?:

(1)a. Entrevistadora: Pero [...] yo creo que pasa más por una cosa de personalidad poh, porque no soy tan de piel, como que me cuesta encariñarme con la gente o darme con la gente, entonces eso puede ser.

M3A7: Pero y ¿en qué-en qué te VTDdai cuenta que VTDeríh como amiga?

b. M8B7: Eeeh, no tenía unos recuerdos y esos recuerdos volvieron el año pasado, en diciembre.

Entrevistadora: Ah, ya. Pero por el tema del embarazo.

M8B7: Claro. Le-eeeh-cuando quedé embarazá' fue sin voluntad, pa' que lo VTDcachíh. En-¿me entiendes? Entonces, esos recuerdos como que yo los había bloqueado y por equis motivo se-como que volvieron a mi mente, pero el año pasado, después de nueve años.

En [1a] la informante, una mujer joven, emplea formas de voseo para preguntarle a su interlocutora (la entrevistadora) por su consideración sobre qué significa para ella la amistad: "¿en qué te dai cuenta que eríh como amiga?". En este caso, aparece la forma eríh, la que hemos evidenciado principalmente en hablantes jóvenes de la zona centro de Chile. En [1b] la informante está relatando una situación muy personal que le sucedió hace ya tiempo. Para ello recurre a información implícita, empleando una forma de voseo en presente de subjuntivo con el verbo cachar: "pa' que lo cachíh", a lo que añade un marcador de tuteo: “ime entiendes?". La alternancia entre la elección morfosintáctica es un rasgo interesante que se da en nuestro corpus, dentro de o entre las distintas categorías:

(2)a. HıB10: Cuidado, no te VTDvayai a resbalar [...], que están en el medio-tus cordones [...]. Te TTDpuedes tropezar con los cordones. Es peligroso.

8 Los casos ilustrados presentan las etiquetas de las respectivas variables estudiadas. En primer lugar se indican los rasgos sociolingüísticos: hombre $(\mathrm{H})$, mujer $(\mathrm{M})$, seguido de su procedencia geográfica (enumeración de norte a sur, considerando 10 zonas urbanas), grupo etario (joven: A; adulto joven: B; adulto: C) y número de identificación dentro del grupo urbano seleccionado (1-18). Asimismo, se señalan las variables lingüísticas: voseo (V), tuteo, (T), ustedeo (U); tratamiento directo (TD), discurso referido (DR), uso no deíctico (ND) y marcador discursivo (MD). En el corpus base todos estos datos se indican siempre en cada una de las formas verbales de segunda singular, pero por razones de simplicidad aquí solo presentamos las etiquetas de las variables lingüísticas.

9 No deja de ser interesante que el voseo sea la forma más utilizada, en cualquiera de sus usos pragmático-discursivos, independiente del contexto comunicativo de interacciones entre desconocidos. 
b. Entrevistadora: Incluso yo soy matemática, no soy-

H8B11: No VTDhueíh

Entrevistadora: No soy tanto de lenguas.

H8Bı1: No me TTDhables de matemáticas.

En [2a] el informante emplea una forma de voseo en presente de subjuntivo para advertir a la entrevistadora sobre una posible caída, pero luego cambia a tuteo para hablar sobre la consecuencia de ese hecho potencial. La utilización de tuteo después de voseo puede deberse a ciertos actos de autocontrol y monitoreo de parte de los hablantes, como vemos en [2b], donde el informante usa una expresión típica del español de Chile a partir del verbo 'huevear', el que se conjuga normalmente con voseo para dirigirse informalmente a un interlocutor y demostrar sorpresa: "no hueíh", para luego pasar a tuteo cuando desea ser explícito sobre su disgusto con un área del conocimiento: "no me hables de matemáticas", lo que más tarde en la conversación aclara, pues había terminado el colegio con nota reprobatoria en esa asignatura. Es importante recalcar que este enunciado además tiene características distintivas de prosodia, en tanto el hablante marca la forma verbal hables con mucho énfasis, lo cual reviste relevancia para nuestro estudio y corrobora nuestra hipótesis sobre el carácter marcado del tuteo frente al voseo ${ }^{10}$.

En general, lo que hemos podido comprobar en nuestros datos es que en la mayor parte de los casos el voseo se utiliza en momentos de espontaneidad y naturalidad, por lo que es frecuente su aparición en construcciones discursivas de bajo monitoreo. Al contrario, el tuteo se emplea en situaciones de mayor autocontrol y conciencia normativa, especialmente cuando el hablante desea proyectar una imagen positiva de sí mismo (Rivadeneira, 2016). Asimismo, se observa que el ustedeo mantiene un carácter básico de respeto, en contextos de relaciones asimétricas, como diferencias generacionales, o en situaciones de poca confianza.

\subsection{Discurso referido}

Esta tipología funcional se refiere en términos generales a la situación comunicativa en la que un hablante reproduce con sus propias palabras un texto oral original como si fuese propio, bien por medio de una construcción discursiva en forma de cita directa, bien por un replanteamiento indirecto (Aikhenvald, 2008). El discurso referido puede incluir a un hablante real, es decir, la persona que produce el discurso referido, al hablante original que produjo el enunciado y a los

10 Compruébese que para cualquier hablante nativo de español chileno no sería natural pronunciar de manera modulada, lenta y enfática una forma de voseo en este mismo contexto. 
participantes dentro del mismo. Según la forma en que se efectúe la reproducción se puede hacer una distinción entre el discurso directo y el discurso indirecto. De estas dos tipologías, en general, se considera que el discurso directo es mucho más utilizado, pues representa no solo un esfuerzo cognitivo mucho menor para los hablantes (Li, 1986), sino que también se ha comprobado que los niños lo aprenden antes y lo utilizan con mayor frecuencia (Ely y McCabe, 1993; Nordqvist, 2001; Köder, 2013). Asimismo, desde un punto de vista pragmático, el estilo indirecto provoca un mayor grado de realce, veracidad y dramatismo en los enunciados (Maldonado, 1999). Desde un planteamiento más específico, San Martín y Guerrero (2013) proponen al menos cinco categorías de discurso directo e indirecto, distinguiendo entre la presencia de marcas prosódicas, gramaticales, léxicas o elementos introductores y el grado de reformulación del enunciado.

En relación al plano de la variación, el discurso referido permite además entrever el carácter de las relaciones sociales de una comunidad de habla y los valores de alternancia en los paradigmas verbales, como puede ocurrir en determinadas áreas geográficas bilingües (Carvalho, 2010). El estudio de esta autora releva un análisis de los diálogos reproducidos y sus alternancias verbales entre los paradigmas de voseo y tuteo, como expresiones relacionadas con la edad o el origen del interlocutor. En este sentido, concordamos con otros autores en la necesidad de investigar este tipo de uso discursivo como herramienta estilística, pues "quotations are sites where speakers use language pragmatically to enact socioculturally locatable identities. Speakers may alternate $t$ - and $v$ - forms in quoted dialogue in order to highlight their and their interlocutors' identities and affiliations, be they local versus outsiders, or young versus old” (Koven, 2001, en Carvalho, 2010: 19).

Como hemos visto, el discurso referido evoca diálogos, conversaciones que el hablante puede guardar como testimonio de interacciones previas - tal vez hipotéticas, ficticias - en las que se representan formas lingüísticas específicas, a veces asociadas a imágenes de uso social. En nuestro corpus, estas representaciones de uso quedan de manifiesto en las construcciones discursivas de los hablantes, en instancias interactivas en las que el/la informante participa como interlocutor:

(3)a. H4B7: Es que igual estábamos pololeando, o sea, andábamos, nunca le pedí pololeo. Entrevistadora: Hasta ahora nunca le hai pedi'o pololeo.

H4B7: No, hasta que un día estábamos-y me dijo "oye, ¿y cuándo me VDRvai a pedir pololeo?" y ahí, recién, le pedí.

b. Entrevistadora: Y carreteabai toda tu plata.

H4B7: Me carreteaba-sí, me hacía harta-una vez mi mamá me dijo "hueón, cómprate algo poh, hueón, cómprate ropa poh, hueón”, no me compraba ni ropa, salía a carretear [...]. Sí poh, fueron tres años hasta que un primo, cachai, me dijo "hueón, a voh te iba bien en el colegio por qué no VDRseguíh estudiando", "no sé, hueón, no sé". Me dijo "hueón, métete a estudiar”. 
En este caso se trata de la representación de una conversación entre el informante y su novia, en una instancia en la que ella sugiere que empiecen una relación más formal: "oye ¿y cuándo me VDRvai a pedir pololeo?". En el segundo caso vemos al mismo informante retratando una interacción con su madre y luego con su primo, en situaciones donde ambos le instan a mejorar en algunos aspectos de su vida personal: "hueón, a voh te iba bien en el colegio por qué no VDRseguíh estudiando", donde se observa además el empleo pronominal de voseo como término de preposición (“a voh”). En ambas instancias, se observa que la utilización de voseo viene dada por un interlocutor hacia el informante. En otros casos, vemos que el empleo de voseo es mutuo en las representaciones:

(4) M6A2: No, yo tengo un amigo que es artesano. Y yo le digo, "quiero estos aros", y le llevo de repente las fotos, se los describo, "ah, ya, te los tengo en tres días más”, "¿y cuánto me VDRcobrai?", "no, lo que tú me VDRquerai pagar”, y siempre me dice eso.

En este ejemplo la informante inicia el discurso referido describiendo una situación en la que ella le pide a un amigo artesano que le confeccione un par de aros. La interacción es retratada por la informante como una conversación informal, en donde se denota confianza: "¿y cuánto me VDRcobrai?", a lo que su interlocutor responde: "no, lo que tú me VDRquerai pagar". Continúa el relato más adelante explicando más detalles sobre los aros:

(5) M6A2: "Quiero algo así, que sea como medio así, que tenga colores, pero que sea de cobre, ¿VDRpodíh hacer algo?”, "no, voy a ver qué me sale”, y me los mostró, "¿te gustaron?”, "si", "ya, toma”. [...] "Págamelos cuando VDRpodai”, y eso es lo otro que me dice, "págalos cuando TDRpuedas".

Es interesante notar que en este último ejemplo la informante reelabora el enunciado de su interlocutor "págamelos cuando VDRpodai" y lo transforma a tuteo "págalos cuando TDR puedas", quizás como un esfuerzo correctivo, pues en la repetición hay cierto grado de explicitación — situación que hemos observado en otras secuencias de nuestro corpus. Este uso de tuteo queda en evidencia en la siguiente secuencia en la que se retrata una situación en donde supuestamente participan varios interactantes ("ahí fue como que le dijimos"), quienes se dirigen a una interlocutora para pedirle un 'cambio de actitud':

(6) H3A9: Sí. Al principio, onda, al principio del semestre, como te dije que como que esto se dio al principio, ahí fue como que le dijimos, onda, "sabíh qué, onda, pa' trabajar contigo, van a haber dos formas", yo siempre le digo dos formas, ¿cachai? "La primera es que TDRcambies tu actitud y TDRtrabajes como en equipo y TDRseas menos exigente, menos crítica, así como crítica agria y más como, no sé, resiliente a algunas cosas y lo otro es que TDRsigas siendo como TDRestás, pero te alejamos de lo que es trabajo en equipo. O sea, te damos pegas individuales, como lo que sería la página web”. 
Es interesante notar los usos de tuteo en este ejemplo como una manera de abordar la situación de forma directa y transparente, con tono serio, severo: "que cambies tu actitud [...], trabajes en equipo [...], seas menos exigente [...], que sigas siendo como estás", lo que, en efecto, corrobora nuestra premisa sobre los usos correctivos del tuteo como forma marcada.

Para cerrar, veamos un último ejemplo de discurso referido con voseo, esta vez una forma que consideramos variante diatópica, donde nos encontramos con una situación en la que una hija se dirige a su madre para pedirle que le cuide a su bebé: "total tú mamá VDRsoh joven, me VDRpodíh cuidar a mi hija".

(7) M6C16: ahora no poh, las mamás modernas ahora le dejan la guagua a la mamá, a la abuela, "total tú mamá VDRsoh joven, me VDRpodíh cuidar a mi hija”, entonces es totalmente distinto y a veces creen que es una obligación, no es como que es una opción de uno "ya yo te la cuido hoy día, pero mañana no puh, no, si te la cuido hoy día", "me la cuida hoy día, mañana también me la tiene que cuidar", entonces es como mucho aprovecharse.

En este caso, la hija se dirige a ella mediante un voseo de tipo mixto verbal, pues combina el pronombre tú con la forma soh (variante morfológica de soi), que se ha detectado como más característica de la zona sur de Chile, especialmente en el lenguaje juvenil (Rivadeneira, 2016).

\subsection{Uso no deíctico}

Como es bien sabido, la deixis es aquella estrategia que nos permite expresar la relación entre el sistema lingüístico, los participantes de una interacción y los factores contextuales (Green, 1995, en Paz, 2001). En el nivel de los participantes se hallan los deícticos de persona, los que incluyen al hablante, el oyente y la audiencia (Fillmore, 1975). Haverkate (1984), por otro lado, plantea que existen tres clases de estrategias de deixis personal: estándar, focalizadora y desfocalizadora. Dentro de estas, la última se caracteriza por minimizar el papel del hablante a través de la impersonalización, supresión de la identidad del agente, empleo de la primera persona del plural inclusivo, uso de referencias inclusivas que enmarcan al hablante, oyente y a un número ilimitado de personas y expresiones de segunda persona del singular a través de las cuales el hablante se distancia del enunciado. Dado nuestro interés investigativo, nos centraremos pues en esta última categoría a través del sistema de tratamiento de segunda de singular, especialmente en aquellos casos en los que la referencia deíctica es inespecífica, indefinida o desfocalizada (Bidot, 2008), de manera tal que el hablante la puede emplear como recurso de distanciamiento para minimizar o reducir su propio rol (Haverkate, 1994) a través de "[un] mecanismo de interferencias de persona [que] puede reducirse a un juego inclusivo-exclusivo de las personas enunciativas respecto de la situación comunicativa, es decir, a un 
mayor o menor distanciamiento entre los interlocutores" (Hidalgo Navarro, 1996-1997: 171). Otros usos no prototípicos incluyen el extender una experiencia a "toda la raza humana" (Seco, 1989: 374), objetivar un enunciado (Serrano y Aijón, 2012; Serrano, 2013) o generalizar por medio de la apertura del vínculo entre el yo y los individuos que conforman el no-yo (Enríquez, 1984, en Hidalgo Navarro, 1996-1997).

Cabe destacar que el empleo de la segunda persona del singular en su función no deíctica es muy frecuente en español coloquial (Seco, 1989; Hidalgo Navarro, 1996; Serrano, 2013). En este sentido, Briz (1995) retoma la noción de encubrimiento al señalar que se trata más bien de un caso de atenuación pragmática del yo.

Al revisar la extensa bibliografía sobre la temática, quedan en evidencia las diferentes posturas con respecto a lo que se concibe como uso no deíctico de la segunda persona, en donde surgen denominaciones como 'generalización', 'impersonalidad', 'despersonalización', 'indefinición', 'encubrimiento', 'distanciamiento', 'desfocalización’, 'objetivación’ y ‘evidencialidad' (Haverkate, 1984, 1994; Kitagawa y Lehrer, 1988; Seco, 1989; Hidalgo Navarro, 1996-1997; Muñiz, 1998; Fernández Soriano y Táboas, 2000; Hollaender, 2002; Aikhenvald, 2008; Bidot, 2008; Fernández, 2008; Hurtado Cubillos, 2009; Hugo, 2011; González y Hugo, 2012; Serrano y Aijón, 2012; Serrano, 2013), las que en el fondo describen distintas estrategias estilísticas: encubrir o impersonalizar el yo, generalizar, compartir una experiencia u objetivar, distanciarse o desfocalizar un enunciado.

Una propuesta que incluye aspectos de variación morfosintáctica en el análisis de los usos no deícticos de la segunda persona de singular se encuentra en Pulido (2015: 16-18), quien además relaciona esta variable con una categorización estilística y pragmático-discursiva de los distintos tipos de usos no prototípicos para el español de Chile, los que la autora denomina 'generalización', 'generalización focalizada’11, 'desfocalización' y 'encubrimiento del yo'. Si bien en el presente estudio no hemos profundizado a nivel de subcategorías, hacemos algunas observaciones con respecto a ciertos usos donde es posible evidenciar estas distintas tipologías.

Los casos de usos no deícticos que encontramos en nuestro corpus corresponden principalmente a construcciones de voseo y tuteo; en este sentido, es interesante el hecho de que no se registran prácticamente casos de ustedeo, pese a que puede haber sido la fórmula seleccionada para el trato directo durante la entrevista (especialmente en los informantes

11 Es interesante notar que la categoría ‘focalizada' se distingue de la generalización típica en tanto su uso va dirigido a un grupo específico de personas, noción que la autora retoma de Bolinger (1979) para los usos no deícticos del inglés. 
del grupo adulto), lo que comprueba que el empleo de tratamiento directo como variante pragmático-discursiva no influye sobre la utilización de los usos no deícticos. Ahora bien, entre los ejemplos que destacamos, surgen escenas comunes en donde el hablante se oculta a sí mismo para objetivar el enunciado:

(8)a. H4B7: Porque mi mamá tomó una mala decisión porque está con un caballero que no me parece, o sea, estaba con un caballero, con una pareja, que no sabe entablar una conversación, tú lo VNDenfrentai como mirándolo a los ojos, cachai, y-y te esquivaba, entonces, hueón, tú le VNDestai hablando algo serio y pasa un gato al la'o y dice "mira el gato",cachai, y te corta la conversación poh, entonces voh VNDdecíh "este hueón es estúpido o se hace".

b. M7C17: Si el casarse es un papel en la parte, digamos-antes, porque uno antes se casaba y le preguntaban “¿Separación de bienes?”, “ino!, ino!, cómo va a ser eso”. ¿Te fijas? “Yo me caso por amor”. Una mierda. El amor tampoco existe, ah. Después-lo que me pasó a mí fue una co-me empecé a acostumbrar. Ya cuando me fue mal económicamente empezaron los problemas, porque cuando tú TNDtienes harta plata todos Ios problemas se solucionan y cuando ya falta la plata empiezan los problemas. Tú TNDpuedes serTNDpuedes amar mucho a tu pareja, pero faltó la cebolla y empezaron los problemas.

En estos casos queda en evidencia el 'yo encubierto' que surge como herramienta estilística de disipación o distanciamiento del enunciado. Así, en [8a] vemos cómo el hablante comenta sobre una situación familiar, personal, que le provoca dificultades de trato, en este caso, con la pareja de su madre: "tú lo enfrentai...", "tú le estai hablando algo serio [...] y te corta la conversación”, "voh decíh 'este hueón es estúpido o se hace””. Observamos, asimismo, que la construcción morfosintáctica con pronombres sujeto (tú, voh) no elimina ni reduce el carácter no deíctico del enunciado. En [8b] el estilo encubierto viene desde la experiencia personal del informante, quien emplea la forma impersonal uno en este contexto con valor de 'inductor de genericidad' (Hernanz, 1990b), elemento que co-aparece en ciertos contextos y que sirve para dotar a los enunciados de un valor genérico: "uno antes se casaba”. Luego se revela la identidad en "yo me caso por amor", y continúa su relato de vivencia personal, "lo que me pasó a mí”, proseguido por más inductores genéricos: “cuando me fue mal económicamente empezaron los problemas", "cuando tú tienes harta plata todos los problemas se solucionan y cuando ya falta la plata empiezan los problemas". Termina esta íntima descripción con usos de tuteo no deíctico: "Tú puedes ser, puedes amar mucho a tu pareja, pero faltó la cebolla y empezaron los problemas".

Otros usos no deícticos hacen referencia a una extensión más colectiva de la experiencia, en lo que se conoce tradicionalmente como 'generalización', es decir, se trata de una situación que ha experimentado el hablante, pero que también puede vivenciar cualquier otra persona: 
(9)a. H5B12: Es que igual las relaciones largas desgastan poh, más que te VNDenamorai, te VNDacostumbrai de la persona, cachai [...]. O como te da pena terminar con esa persona, cachai, [...] VNDsentíh la presión de no ser el hueón malo.

b. M7B12: Los cabros son niños. TNDEstás todo el día ahí, TNDtienes todos los problemas de ellos cuando TNDtienes una jefatura. Si este tiene problemas con la mamá, si el papá-si están cesantes, todos esos problemas son tuyos, cachai. VND'Tai todo el día con esos problemas y los chicos te llaman. Te llaman y te cuentan sus cosas todo el día. VNDLlegas a tu casa ¿y otro niño?

En [9a] se retrata la experiencia de tener una relación amorosa de larga duración —atribuible a cualquier ser humano - como un hecho cotidiano que pasa a convertirse en un hábito, una 'costumbre': "más que te enamorai, te acostumbrai de la persona", "te da pena terminar con esa persona [...], sentíh la presión de no ser el hueón malo". El caso [9b] es levemente distinto a los anteriores, en tanto se proyecta una situación que no es totalmente generalizada, sino que se 'focaliza' en determinado grupo de personas (en este ejemplo, en las profesoras de enseñanza básica y media, mujeres, potenciales madres: "Estás todo el día ahí, tienes todos los problemas de ellos cuando tienes una jefatura", "Tai todo el día con esos problemas", “Llegas a tu casa ¿y otro niño?”). Es interesante destacar que, si bien esta misma informante emplea voseo durante gran parte de la conversación, en esta secuencia discursiva elige formas de tuteo, tal vez para representar de mejor manera el hecho de estar cumpliendo una imposición de su trabajo ('estar todo el día ahí', 'tener que lidiar con problemas', 'tener un cargo de jefatura').

\subsection{Marcadores discursivos}

Los marcadores discursivos son unidades lingüísticas invariables cuya función es la de guiar la conversación (Martín Zorraquino y Portolés, 1999). A nivel prosódico, estas unidades están definidas por la entonación, mientras que en la escritura suelen situarse entre comas. Morfológicamente son unidades lingüísticas que no varían y que pertenecen a diferentes categorías gramaticales, tales como interjecciones, adverbios o locuciones; sintácticamente, no se encuentran integradas en la oración y su posición no está preestablecida; semánticamente, carecen de contenido referencial y tienen la función de guiar las inferencias de una situación comunicativa (Martín Zorraquino y Portolés, 1999). De interés para esta investigación son los marcadores que en el plano gramatical pertenecen a la categoría de verbos de segunda persona singular. Dentro de las categorías propuestas por Martín Zorraquino y Portolés (1999) se encuentran los marcadores enfocadores de alteridad, como mira u oye, marcadores de control de contacto, como fíjate (tú), y marcadores que demuestran el deseo de control de la recepción del mensaje, como ¿me entiendes? 
Bentivoglio y Weber (1999) realizan un estudio sobre del verbo saber en el español hablado de Venezuela, dentro del cual también analizan la función marcadora del discurso del verbo. Las autoras señalan que la forma tú sabes, como marcador, "parece emplearse cuando el hablante quiere cerciorarse de la aprobación o cooperación del oyente” (102). Además, especifican que cuando es marcador su significado no es el de conocer una cosa o tener noticias sobre algo, sino que más bien es decirle al interlocutor "tú y yo tenemos algo en común, pertenecemos al mismo grupo, compartimos algo". Cuenca y Marín (2000) realizan un estudio basado en el análisis de verbos de percepción gramaticalizados como conectores. En su trabajo, las autoras señalan que, cuando actúan como conectores, los verbos de percepción visual ver y mirar y los de percepción auditiva oír y escuchar corresponden al tipo semántico de la percepción sensorial (Cuenca y Marín, 2000: 216). Asimismo, las autoras afirman que, al compartir características, estos conectores pueden analizarse de forma similar tanto desde el punto de vista semántico como desde el morfosintáctico y señalan que estas partículas tienen carácter paréntico; son formas imperativas o relacionadas con el imperativo, pues tienen un valor conativo básico que las relaciona con el receptor y la segunda persona singular, y manifiestan un valor fático relacionado con la conversación, por lo que son formas típicas del discurso oral (Cuenca y Marín, 2000: 216).

Por su parte, Gille (2013) realiza un trabajo acerca de los marcadores discursivos cachai, viste y te fijai al inicio de turno en el español de Chile. El autor denomina estas partículas 'apéndices de intersubjetividad comprobativos' (Gille, 2013: 468). Por medio del análisis realizado sobre un corpus de habla semiespontánea el autor determina que, cuando se presentan al inicio de turno, estos marcadores gramaticalizados se emplean como reguladores del turno de habla o como herramientas argumentativas que permitan reforzar las ideas formuladas. Siguiendo el trabajo de Gille, Méndez y Mondaca (2015) realizan una clasificación exhaustiva sobre el empleo de cachai en Chile y proponen una serie de funciones pragmáticas diferentes, entre las que destacan el actuar como 'captador de atención', 'solicitador de aprobación', 'herramienta argumentativa', 'organizador discursivo' y 'autorregulador'. Cabe destacar que, de todos los marcadores conversacionales que se emplean en el discurso oral del español de Chile, cachai es sin duda el más frecuente (Pons y Samaniego, 1998; San Martín, 2011; Méndez y Mondaca, 2015; Mondaca, Méndez y Rivadeneira, 2015). Con respecto a la etimología de cachar, existen diversas hipótesis, como la que señala que proviene del préstamo inglés to catch, de cuya definición se entiende "entender, comprender"12. Gille (2015), por otro lado, propone como origen el lexema de latín catar o catear, de tal forma que catear > catiar > cachar. Sin embargo, la premisa de Gille (2015) no parece probable, pues carece de sustento histórico,

12 El Diccionario de uso del español de Chile entrega para cachar cuatro acepciones relacionadas con el mismo campo semántico de to catch: 1) percibir con la visión o los oídos; 2) conocer, tener conocimiento; 3) entender, comprender; y 4) suponer, creer. 
en tanto el único registro escrito que se conoce de esta forma aparece por primera vez en la novela Palomita Blanca (1971). Independiente de su origen, lo cierto es que la conjugación de este verbo en la segunda persona de singular se restringe morfológicamente al voseo y casi exclusivamente al presente de indicativo, aunque también es posible su uso en otros tiempos y modos: cacha, cachabai, cacharai, etc. No obstante, la función sintáctica de cachai es significativamente menor en comparación con el alto índice de ocurrencia que presenta como marcador conversacional en los estilos de conversación espontánea y semiespontánea (Rivadeneira, 2016). En relación a otros marcadores, además de cachai, se encuentran ejemplos documentados en Chile tales como te fijai, sabíh/sabes, (me) entendíh/entiendes, entre otros (Méndez y Mondaca, 2015).

En línea con lo anterior, en nuestros datos se constata una elevada frecuencia de uso ${ }^{13}$ del marcador cachai en secuencias donde se evidencia su valor básico de captar y solicitar aprobación del interlocutor:

(10) H2B11: Antes no era así, antes era muy espontáneo, ¿VMDcachai? De hecho, un amigo que estaba muy enamorado de Valparaíso, que vivía ahí y yo lo iba a ver, pasábamos por las calles, me dijo, "Yo me voy de esta cuestión, porque a mí, desde que lo fundaron como patrimonio, dejó de existir lo que yo sentía”. [...] Y se fue a Santiago. [...] Sí poh, pasó a ser una cuestión-yo también, cuando fui, como si me estuvieran paseando como turista, ¿VMDcachai?

Entrevistadora: Sí

H2B11: No como una persona que atraviesa una ciudad, ¿VMDcachai? Me pasó una cosa así. Ya hace rato que yo le he perdido harto el encanto.

El empleo de cachai puede ocurrir en distintas posiciones, pero es sobre todo a final de enunciado donde se percibe que el hablante solicita la aprobación de su interlocutor. En otro tipo de usos es frecuente la aparición de cachai en contexto lingüístico con el reformulador o sea:

(11) H2B11: El día jueves, ya, vuelvo a hacer clases en la mañana, ¿VMDcachai?, en la tarde quedo libre y el viernes hago clases como hasta las cuatro de la tarde. Entonces, igual es como, ¿VMDcachai?, o sea, tampoco es tan así como que-de repente me faltan más proyectos, más cosas poh, ¿VMDcachai?, como pa’ poder yo también tener más estabilidad, de repente pegarme la virá’ también.

13 Cuando nos referimos a una ocurrencia elevada, es porque en nuestro corpus se constata que la frecuencia de uso de la forma cachai es muy superior al resto de marcadores discursivos (en una relación de 5000 a 100). 
Cachai también alterna con el marcador sabíh, forma que suele ir acompañada del relativo que, y cuyo valor consideramos equivalente a un captador de atención, con intencionalidad clara: 'escucha y presta atención a lo que te voy a decir':

(12) MıAI: Sí poh, y esos máster-es que VMDsabíh que, mira, si tú a él le dices, VMDcachai, y un día se anima, dile que en cuanto a máster para aprender a traducir programas, videojuegos, cosas así, a España, ¿ya? A España, que no pesque los de acá.

En el ejemplo [12] además se observa el uso de mira, marcador de alteridad que además sirve de apoyo al valor fático recién descrito. Asimismo, se observa el carácter gramaticalizado de cachai y sabíh en alternancia con los otros usos pragmático-discursivos de la segunda persona:

(13)a. M6B9: Todo el rato la defendía, pero esa fue una de las peleas, no le importó nada, me acuerdo que después dijo "VDRMDsabíh que más, me voy también” y yo "ah, me voy contigo", la dejamos sola trabajando a la señora, teníamos que salir a las cinco de la tarde y nos fuimos como a las dos, y nos fuimos no más poh.

b. M6Bg: Io pasé muy mal, teníamos que preparar tragos, probarlos, obviamente tú no lo tenías que tragar, tenías que escupirlo, pero con el nerviosismo te lo tragabas, te daba miedo la profesora, VMDcachai, hacías todo al revés, pero fue terrible casi me eché el ramo por no saber nada.

En [13a] se observa una estructura sintáctica incluso un poco más compleja, de uso cotidiano en el español chileno coloquial: "sabíh que más...", forma que en el ejemplo se presenta como uso lexicalizado dentro de un enunciado de discurso referido, mientras que en [13b] se constata el empleo de cachai en medio de secuencias de usos no deícticos de tuteo: "tú no lo tenías que tragar, tenías que escupirlo [...], te lo tragabas [...], cachai, hacías todo al revés".

Es interesante destacar que el empleo de marcadores de voseo se da de preferencia en el lenguaje de jóvenes y adultos jóvenes. En algunos hablantes más adultos se observan casos con tendencia al empleo de tuteo:

(14) M7C17: Porque cuando tú pololeas te despides de tu pololo en la puerta de tu casa y el problema del pololo quedó allá y el problema de tu casa quedó acá. Te casaste, fue un problema. ¿Te TMDfijas? Yo-a mí no me interesaba si el pololo tenía problemas en la casa, si no pagaba el arriendo o no pagaba la letra a mí no me interesaba, yo estaba en mi casa, feliz de la vida, te TMDfijas, pero ya cuando se juntan, ya esos problemas son de uno. Esos problemas quedan dentro de la casa. Que "chuta, TMDsabes que, no nos alcanzó la plata”. Yo creo que el factor más grande de las separaciones es la plata, o sea, lo que mueve toda esta vida es la plata. 
En el ejemplo, la informante utiliza formas de tuteo no deíctico "cuando tú pololeas te despides de tu pololo...", en alternancia con el marcador "te fijas". En este caso la hablante recurre además a usos estilísticos como: la primera persona, "Yo-a mí no me interesaba...", "yo estaba en mi casa feliz", la forma impersonal uno, "esos problemas son de uno" y discurso reproducido, en donde inserta el marcador sabes: "chuta, sabes que, no nos alcanzó la plata".

Por último, incluimos un par de ejemplos de marcadores discursivos de ustedeo, los que, si bien son escasos, presentamos por un interés de tipo más diatópico, pues corresponden a usos de informantes de la zona sur austral del país ${ }^{14}$.

(15)a. H10C15: La cosa que cuando llegó esa lancha yo qué alegría, dije, "oh, una lancha nueva llegó y grande que nos va a ayudar". [...] UDRSabe que el primer día que salieron fueron a esa parte donde nos pescó el temporal [...]. Ahí [...] hay un loco que lo llaman loco degenera'o, que ese loco no crece, pero es comestible poh. Tampoco es chico, ¿me UDRentiende?

b. M8C15: y cuando está muy bonito. No UMDve que antes la gente, cuando nosotros íbamos a acampar, no... Iba a acampar en carpa no má'. Este, como este lugar tú te acostumbrabas, cuando éramos chicos los papás nos Ilevaban y... y "nos vamos" y listo.

Evidenciamos, por un lado, marcadores compuestos de estructuras con relativos, tales como sabe que y no ve que — forma que por lo general va precedida del adverbio de negación no y, por otro lado, estructuras que requieren de clítico, como "me entiende", todas funciones en el nivel pragmático de captar atención y solicitar aprobación, especialmente en este último caso.

\section{Conclusiones y discusión}

Hemos descrito y analizado los diversos usos de la segunda persona de singular en el español de Chile, fuera del conocido ámbito deíctico o tratamiento directo hacia el interlocutor. En general, comprobamos que la propuesta de Biq (1991) para el chino mandarín se puede implementar muy bien en una lengua como el español, pudiendo ser considerada como una tipología de usos equivalentes, donde se evidencian rasgos 'multifuncionales' de una misma unidad lingüística. Así, observamos, por un lado, que las categorías propuestas en este trabajo se ajustan a usos de la lengua oral como estrategias comunicativas, con funciones estilísticas específicas, como lo son demostrar emociones o estados de ánimo concretos (como empatía, cercanía, desconfianza, sorpresa, miedo, tristeza, entre muchos otros), proyectar imágenes

14 Específicamente de Chiloé, Coyhaique y Punta Arenas. 
positivas (o también negativas) de uno mismo o de terceros, dramatizar un suceso, extender experiencias personales hacia otros, hacer que una opinión suene más objetiva o simplemente mantener el contacto abierto y la atención del interlocutor durante una conversación. En el fondo, cada una de las dimensiones descritas responde a una multifuncionalidad, la cual planteamos forma parte integral del sistema de segunda persona: el trato directo (deíctico), el discurso referido, los usos no deícticos y los marcadores discursivos. En concreto - si bien no nos hemos abocado aquí a cuestiones cuantitativas - destacamos como resultados de nuestro análisis que el empleo de voseo es extendido en todas las categorías, a diferencia del tuteo y ustedeo, que parecen perder terreno en una conversación semi-espontánea. Es importante también señalar que existe un grado de empatía en el tratamiento de voseo que no se halla presente en las otras dos formas. En concordancia con lo anterior, el voseo parece estar en una etapa de incorporación avanzada en la norma culta, especialmente en cuanto al grado de uso por parte de los hablantes, lo que podría ser indicativo de un cambio lingüístico en desarrollo, tal y como se ha propuesto en estudios empíricos previos (Rivadeneira, 2009; Torrejón, 2010b; Rivadeneira y Clua, 2011; Rivadeneira, 2016). En cuanto al tuteo, se corrobora el carácter más neutro (Hummel, 2010) e incluso marcado, frente al voseo, en situaciones simétricas informales (Rivadeneira, 2016) en las que se denota cierto grado de desconfianza. En relación al ustedeo, Ilama la atención su escasa aparición en nuestro corpus, lo que tal vez pueda deberse también a un cambio lingüístico, pero esta vez indicativo de retroceso, porque podría ser un rasgo más propio y restringido al trato entre y hacia hablantes de generaciones más mayores (las que no hemos contemplado aquí). En cualquier caso, las instancias que detectamos en nuestros datos corresponden a situaciones cuyo tratamiento básico es el respeto.

Para cerrar, quisiéramos destacar el hecho de que el presente estudio se conforma como la primera investigación que integra las diversas dimensiones de uso de la segunda persona en español en un corpus que, aunque exploratorio, no deja de ser menor, además de reunir datos de distintas zonas geográficas y hablantes de distintos grupos generacionales. En este sentido, retomamos nuestro planteamiento inicial sobre la necesidad de realizar investigaciones empíricas que contribuyan a describir y analizar no solo los niveles lingüísticos fundamentales, sino también aquellas dimensiones superiores de la lengua que son representativas del conocimiento personal y social de una comunidad de habla, en este caso, como la de Chile, región dialectal única y exclusiva dentro de Hispanoamérica (Ĉerný, 1999; Benavides, 2003).

\section{Agradecimientos}

La primera autora de este trabajo agradece el financiamiento de CONICYT a través del proyecto FONDECYT No 11110211 . De igual forma, se agradece el apoyo constante y desinteresado de Eliana Valenzuela y Marcelo O. Rivadeneira, así como la colaboración logística de Eduardo Vé- 
liz, Jaime Coronil, Marcelo Michel, Stefanía Romero, Karen Barra, Nicol Lara y Andrea Méndez por compartir sus contactos en las distintas ciudades de muestreo. Por último, se dan gracias especiales a Erico, Montserrat y Marshall Carmona por fomentar la investigación lingüística en los confines del mundo.

\section{Bibliografía citada}

Aikhenvald, Alexandra, 2008: "Semi-direct speech: Manambu and beyond", Language Sciences 30, 383-422.

Araya, Ángel, 1995: "Variaciones sociolingüísticas del voseo en la Relación Autobiográfica de Úrsula Suárez (1666-1749)" en Hermógenes Perdiguero y Antonio Álvarez (eds.): Estudios sobre el español de América, actas del V Congreso Internacional de El Español de América, Burgos.

Benavides, Carlos, 2003: “La distribución del voseo en Hispanoamérica”, Hispania 86(3), 612-623.

Bentivoglio, Paola, y Elizabeth G. Weber, 1999: “El perfil discursivo del verbo saber en el español hablado en Venezuela" en Eduardo Forastieri Braschi, Julia Cardona, Humberto López Morales, Amparo Morales de Walters (eds.): Estudios de lingüística hispánica: homenaje a María Vaquero, Puerto Rico: Editorial de la Universidad de Puerto Rico.

BertolottI, Virginia, 2004: "Tuteo y voseo en el Uruguay durante el siglo XIX", comunicación del III Congreso Brasileiro de Hispanistas, Universidade Federal de Santa Catarina, Florianopolis.

BIDOT, Irina, 2008: "La desfocalización del centro deíctico personal a través de la segunda persona del singular”, Boletín de Lingüística 20(30), 62-87.

BIQ, Yung-O, 1991: "The multiple uses of the second person singular pronoun $n i$ in conversational Mandarin", Journal of Pragmatics 16, 307-321.

Blas Arroyo, José Luis, 1995: "Un ejercicio de sociolingüística interaccional: el caso de los pronombres de tratamiento en el español actual”, Verba 22, 229-252.

Bolinger, Dwight, 1979: “To catch a metaphor: you as norm”, American Speech: A quarterly of Linguistic Usage 54(3), 194-209.

BRIz, Antonio, 1995: "La atenuación de la conversación coloquial. Una categoría pragmática” en actas del I Simposio sobre el español coloquial. Aspectos del discurso oral, Almería: Universidad de Almería. 
Carricaburo, Norma, 2004: "El voseo en la Historia y en la lengua de hoy" [disponible en http:// www.elcastellano.org/ns/edicion/2004/julio/voseo.html].

Carvalho, Ana María, 2010: “¿Eres de la frontera o sos de la capital? Variation and alternation of second-person verbal forms in Uruguayan border Spanish”, Southwest Journal of Linguistics 29, 1-23.

ĈERNÝ, Jiří, 1999: "Observaciones sobre el español hablado en América”, Iberoamericana Olomucensia I, Romanica Olomucensia VIII, Philologica 74, 39-48.

Cuenca, María Josep, y María Josep Marín, 2000: "Verbos de percepción gramaticalizados como conectores. Análisis constrativo español-catalán”, Revista española de lingüística aplicada, volumen monográfico, 215-237

Dworkin, Steven, 1988a: "The interaction of phonological and morphological processes: the evolution of Old Spanish second person plural verb endings", Revue de Philologie 42, 144-155.

DWoRkIn, Steven, 1988b: "The diffusion of a morphological change: the reduction of the Old Spanish verbal suffixes -ades, -edes and-ides", Medioevo Romanzo 13, 223-236.

Eguiluz, Luisa, 1962: "Fórmulas de tratamiento en el español de Chile", Boletín de Filología de la Universidad de Chile 14, 169-233.

Ely, Richard, y Allyssa McCABE, 1993: "Remembered voices", Journal of Child Language 20, 671-696.

EnRiQuez, Emilia, 1984: El pronombre personal sujeto en la lengua española hablada en Madrid, Madrid: CSIC.

Fernández, Susana S., 2008: "Generalizaciones y evidencialidad en español”, Revue Romane 43(1), 63-80.

Fernández Mallat, Víctor, 2011: "El 'voseo mixto verbal' de hablantes chilenos en Montreal: Estudio de caso en un contexto de contacto dialectal", Boletín de Filología de la Universidad de chile 46(2), 35-58.

Fernandez Soriano, Olga, y Susana Táboas, 2000: "Construcciones impersonales no reflejas" en Ignacio Bosque y Violeta Demonte (eds.): Gramática descriptiva de la lengua española, vol. II, Madrid: Espasa Calpe, 1723-1778.

Fillmore, Charles, 1975: Santa Cruz Lectures on Deixis, Bloomington: Indiana University Press. 
Fontanella de Weinberg, María Beatriz, 1970: “La evolución de los pronombres de tratamiento en el español bonaerense", Thesaurus 25(1), 12-22.

Fontanella de WeinBerg, María Beatriz, 1971: "El voseo en Buenos Aires en las dos primeras décadas del siglo XIX”, Thesaurus 26(3): 495-514.

Fontanella de Weinberg, María Beatriz, 1977: "La constitución del paradigma pronominal del voseo", Thesaurus 32, 227-241.

Fontanella de Weinberg, María Beatriz, 1979: “La oposición ‘cantes/cantés' en el español de Buenos Aires", Thesaurus 34, 72-83.

Fontanella de Weinberg, María Beatriz, 1987: El español bonaerense, cuatro siglos de evolución lingüística, 1580-1980, Buenos Aires: Hachette.

Fontanella de Weinberg, María Beatriz, 1993: "Usos americanos y peninsulares de segunda persona de singular: siglos XVI y XVII" en Luis Martínez CuItIÑo y Elida LoIs (eds.): actas del III Congreso Argentino de Hispanistas, España en América y América en España, Buenos Aires: Universidad de Buenos Aires, 144-153.

Fontanella de Weinberg, María Beatriz, 1999: "Sistemas pronominales de tratamiento usados en el mundo hispánico" en Ignacio Bosque y Violeta Demonte (eds.): Gramática descriptiva de la lengua española, tomo 1, Madrid: Real Academia Española / Espasa Calpe, 1399-1425.

García, Erica, 1986: "El fenómeno (de)queísmo desde una perspectiva dinámica del uso de la lengua”, en José Moreno de Alba (ed.): actas del II Congreso Internacional sobre El Español de América, México: Universidad Nacional Autónoma de México, 46-65.

Guerrero, Silvana, 2011a: "Diferencias de género en evaluaciones de narraciones de experiencia personales en el habla juvenil de Santiago de Chile. Una aproximación sociolingüística”, Revista Signos. Estudios de Lingüística 44(75), 18-32.

Guerrero, Silvana, 2011b: "Análisis sociolingüístico de las diferencias de género en patrones narrativos de historia de experiencia personal en el habla juvenil de Santiago de Chile", Boletín de Filología de la Universidad de Chile 46(2), 85-106.

GILLE, Johan, 2013: "Sobre el uso de los marcadores discursivos cachái, viste y te fijái al inicio de turno" en Neyla Pardo, Denize García, Teresa Oteiza y María Asqueta (eds.): Estudios del discurso en América Latina: Homenaje a Ana María Harvey, Bogotá: Asociación Latinoamericana de Estudios del Discurso, 465-484. 
GILLE, Johan, 2015: “Los apéndices conversacionales en la argumentación: El caso de ¿cachái?” en Gunner Engwall y Lars Fant (eds.): Festival Romanistica. Contribuciones lingüísticas - Contributions linguistiques - Contributi linguistici - Contribuições lingüísticas, Stockholm: Stockholm University Press, 239-258.

GonzÁlez, Carlos, 2002: “La variación 'eríh'/‘soi’ en el voseo verbal de Santiago de Chile. Un estudio exploratorio”, Onomázein 7, 213-230.

GonzAlez, Carlos, y Evelyn Hugo, 2012: “'Cuando te lo piden, uno no siempre sabe qué decir’ Uno y tú como estrategias evidenciales en el español de Chile" en actas del IV Congreso Internacional de Letras, Transformaciones Culturales. Debates de la teoría, la crítica y la lingüística en el Bicentenario, Buenos Aires, Facultad de Filosofía y Letras de la Universidad de Buenos Aires, 647- 654.

GreEn, Keith, 1995: "Deixis: A Revaluation of Concepts and Categories" en Keith Green (ed.): New Essays in Deixis: Discourse, Narrative, Literature, Amsterdam/Atlanta: Rodopi B. V.

Haverkate, Henk, 1984: Speech acts, speakers and hearers, Amsterdam: John Benjamins.

Haverkate, Henk, 1994: La cortesía verbal. Estudio pragmalingüístico, Madrid: Gredos.

Helincks, Kris, 2015: "Negotiation of Terms of Address in a Chilean Television Talk Show", Bulletin of Hispanic Studies 92(7), 731-752.

Hernanz, María Luisa, 1990: "En torno a los sujetos arbitrarios: la za persona del singular" en Violeta Demonte y Beatriz Garza Cuarón (eds.): Estudios de lingüística de España y México, México: UNAM, 151-178.

Hidalgo, Antonio, 1996-1997: "Sobre los mecanismos de impersonalización en la conversación coloquial”, ELUA 11, 163-176.

Hollaender Jensen, Mikkel, 2002: "La referencia en algunas expresiones impersonales. Diferentes lecturas de uno y la segunda persona del singular”, Romansk Forum 16(2), 127-138.

Hugo, Evelyn, 2011: “Las formas de segunda persona singular como estrategias evidenciales”, Revista de Lingüística Aplicada 49 (1), 143-167.

Hummel, Martin, 2010: "Reflexiones metodológicas y teóricas sobre el estudio de las formas de tratamiento en el mundo hispanohablante, a partir de una investigación en Santiago de Chile" en Martin Hummel, Bettina Kluge y María Eugenia Vazquez (eds.): Formas y fórmulas de 
tratamiento en el mundo hispánico, México, D. F.: El Colegio de México / Graz, Austria: KarlFranzens-Universität, 101-162.

Hummel, Martin; Bettina Kluge y María Eugenia Vazquez Laslop, 2010: Formas y fórmulas de tratamiento en el mundo hispánico (eds.): México, D. F.: El Colegio de México / Graz, Austria: KarlFranzens-Universität.

Hurtado Cubillos, Luz Marcela, 2009: “La expresión de la impersonalidad en el español de Chile”, Cuadernos de Lingüística Hispánica 13, 31-42.

Kitagawa, Chisato, y Adrienne Lehrer, 1990: "Impersonal uses of personal pronouns", Journal of Pragmatics 14, 739-759.

KöDER, Franziska, 2013: "Pronoun interpretation in direct and indirect speech" en actas del Sixth Colloquium of Semantics and Philosophy in Europe, Saint-Petersburg: Saint Petersburg State University.

KLuge, Bettina, 2005b: "Las fórmulas de tratamiento en un corpus chileno" en Volker Noll, Klaus Zimmermann e Ingrid Neumann-Holzschum (eds.): El español en América: Aspectos teóricos, particularidades, contactos; Lengua y sociedad en el mundo hispánico, 11, Frankfurt am Main / Madrid: Vervuert/Iberoamericana, 169-188.

Koven, Michelle, 2001: “Comparing bilinguals' quotes: performances of self and others in telling of the same experience in two languages”, Languages in Society 30, 513-558.

LABOV, William, 1972b: Language in the inner city, Philadelphia: University of Pennsylvania Press.

Lafourcade, Enrique, 1971: Palomita Blanca, Santiago de Chile: Editorial Zigzag.

LAVANDERA, Beatriz, 1978: "Where does the sociolinguistic variable stop?", Language in Society 7, 171-182.

LI, Charles N., 1986: "Direct and indirect speech: A functional study" en Florian Coulmas (ed.): Direct and Indirect Speech, Berlin / New York / Amsterdam: Mouton de Gruyter, 29-45.

Maldonado, Concepción, 1999: "Discurso directo y discurso indirecto" en Ignacio Bosque y Violeta Demonte (eds.): Gramática descriptiva de la lengua española, Madrid: Espasa Calpe, 35493596. 
Martín Zorraquino, María Antonia, y José Portolés, 1999: "Los marcadores del discurso" en Ignacio Bosque y Violeta Demonte (eds.): Gramática descriptiva de la lengua española, vol. 3, Madrid: Espasa Calpe, 4051-4212.

Méndez, Andrea y Mondaca, Lissette, 2015: "No es muletilla, es marcador, ¿cachái?”. Análisis de la función pragmática del marcador discursivo conversacional cachái en el español de Chile. Tesis de licenciatura, inédita, Temuco: Universidad Católica de Temuco.

Mondaca, Lissette, Andrea Méndez y Marcela Rivadeneira, 2015: “No es muletilla, es marcador, ¿Cachái?’. Análisis de la función pragmática del marcador discursivo conversacional cachái en el español de Chile”, Literatura y Lingüística 32, 233-258.

Morales Pettorino, Félix, 1998-1999: "Panorama del voseo chileno y rioplatense”, Boletín de Filología de la Universidad de Chile 37, 835-848.

Moreno Fernández, Francisco, 2009 [1998]: Principios de sociolingüística y sociología del lenguaje, Barcelona: Ariel.

Muñız, Carmen, 1998: Impersonalidad y despersonalización. Estudio contrastivo, Oviedo: Universidad de Oviedo.

NordQvist, Åsa 2001: Speech about speech. A developmental study on form and functions of direct and indirect speech, Göteborg: Kompendiet.

PAz, Yanira, 2001: "Deixis personal, social y discursiva en narrativas orales de El Empedrao (Maracaibo, Venezuela)", Revista Signos, Estudios de Lingüística 34(49-50), 89-97.

Pons, Hernán, y José Luis Samaniego, 1998: "Marcadores pragmáticos de apoyo discursivo en el habla culta de Santiago de Chile”, Onomazein 3, 11-25.

Pulido, Paulina, 2015: Análisis contrastivo de las funciones pragmáticas de la segunda persona del singular no deíctica en español y en inglés. Tesis de licenciatura, inédita, Temuco: Universidad Católica de Temuco.

Rivadeneira, Marcela, 2009: El voseo en medios de comunicación de Chile. Descripción y análisis de la variación dialectal y funcional. Tesis doctoral, Barcelona: Universitat Pompeu Fabra.

RivadeneIRA, Marcela, 2016: "Sociolinguistic variation and change in Chilean voseo" en María Irene Morna y Susana Rivera-Mılıs (eds.): Forms of address in the Spanish of the Americas, Amsterdam: John Benjamins. 
Rivadeneira, Marcela, y Esteve Clua, 2011: "Una visión desde el análisis de la variación dialectal y funcional en medios de comunicación", Hispania 94(4), 680-703.

Rivadeneira, Marcela, y Violeta Cautín-Epífani, 2015: "Las formas de tratamiento en el español de Chile. Una aproximación a la variación lingüística en documentos históricos del siglo XVII”, comunicación en el Coloquio de Lingüística Histórica, Santiago: Pontificia Universidad Católica de Chile.

SAnkoff, Gillian, 1973: "Above and beyond phonology in variable rules" en Charles-James N. BAILEy y Roger W. Shuy (eds.): New ways of analyzing variation in English, Washington, DC: Georgetown University Press, 44-62.

SANKoff, David, 1988b: "Sociolinguistics and syntactic variation" en Frederick J. NewmeYer (ed.): Linguistics: the Cambridge survey, Cambridge: Cambridge University Press, 140-161.

SAn Martín, Abelardo, 2004-2005: "Igual como marcador discursivo en el habla de Santiago de Chile: Función pragmático-discursiva y estratificación social de su empleo”, Boletín de Filología de la Universidad de Chile 40, 201-232.

SAN MARtín, Abelardo, 2011: "Los marcadores interrogativos de control de contacto en el corpus PRESEEA de Santiago de Chile”, Boletín de Filología de la Universidad de Chile 46(2), 135-166.

San Martín, Abelardo, y Silvana Guerrero, 2013: "Una aproximación sociolingüística al empleo del discurso referido en el corpus PRESEEA de Santiago de Chile”, Revista Signos. Estudios de Lingüística 46(82), 258-282.

Seco, Manuel, 1989: Gramática esencial del español, Madrid: Espasa-Calpe.

SerRano, María José, 1999: Estudios de variación sintáctica, Madrid/Frankfurt: Iberoamericana/ Vervuert.

Serrano, María José, 2013: "El pronombre tú como recurso objetivador en español: variación textual y discursiva”, Borealis, An International Journal of Hispanic Linguistics 2(1), 179-197.

Serrano, María José, y Miguel Ángel Aijón Oliva, 2012: "Cuando tú eres yo: la inespecificidad referencial de tú como objetivación del discurso", Nueva Revista de Filología Hispánica 60(2), 541-563.

Silva-Corvalán, Carmen, 2001: Sociolingüística y pragmática del español, Washington DC: Georgetown University Press. 
SweEney, Patricia, 2013: El voseo en Chile: Factores histórico-morfológicos que explican su aparición y mantenimiento, Denver: Outskirst Press.

Tagliamonte, Sali, 2006: Analysing Sociolinguistic Variation, New York: Cambridge University Press.

Torrejón, Alfredo, 1986: “Acerca del voseo culto de Chile”, Hispania 69(3), 677-683.

ToRrejón, Alfredo, 1991: "Fórmulas de tratamiento de segunda persona singular en el español de Chile”, Hispania 74(4), 1068-76.

Torrejón, Alfredo, 2010a: “El voseo en Chile: Una aproximación diacrónica” en Martin Hummel, Bettina Kluge y María Eugenia Vázquez (eds.): Formas y fórmulas de tratamiento en el mundo hispánico, México, D. F.: El Colegio de México / Graz, Austria: Karl-Franzens-Universität, 413-427.

Torrejón, Alfredo, 2010b: “Nuevas observaciones sobre el voseo en el español de Chile” en Martin Hummel, Bettina Kluge y María Eugenia Vázquez (eds.): Formas y fórmulas de tratamiento en el mundo hispánico, México, D. F.: El Colegio de México / Graz, Austria: Karl-Franzens-Universität, 755-769. 